\title{
The relationship between anxiety and overactive bladder/urinary incontinence symptoms in the clinical population
}

\author{
H Henry Lai ${ }^{1,2}$, Amar Rawal $^{1}$, Baixin Shen ${ }^{1}$, and Joel Vetter ${ }^{1}$ \\ ${ }^{1}$ Division of Urologic Surgery, Department of Surgery, Washington University School of Medicine, \\ St Louis, MO 63110, USA \\ ${ }^{2}$ Department of Anesthesiology, Washington University School of Medicine, St Louis, MO 63110, \\ USA
}

\section{Abstract}

Objective-To investigate the relationship between anxiety and overactive bladder/urinary incontinence symptoms among clinical population.

Methods-Patients who were diagnosed with overactive bladder (OAB) and age-matched control subjects without $\mathrm{OAB}$ were enrolled. Anxiety symptoms were assessed using the Hospital Anxiety and Depression Scale (HADS-A). OAB/incontinence symptoms were assessed using the ICIQ-UI, ICIQ-OAB, UDI-6, IIQ-7, and OAB-q. Other psychosocial factors were also assessed.

Results-About half of the OAB subjects (48\%) had anxiety symptoms, and one quarter of OAB subjects $(24 \%)$ had moderate to severe anxiety. OAB subjects reported significantly higher anxiety symptoms compared to age-matched controls (HADS-A: $7.5 \pm 4.5$ versus $3.3 \pm 3.6, \mathrm{p}<0.001$ ). $\mathrm{OAB}$ subjects with anxiety reported more severe $\mathrm{OAB} /$ incontinence symptoms, greater bother and impact on quality of life compared to OAB subjects without anxiety (ICIQ-UI, ICIQ-OAB, UDI-6, IIQ-7, OAB-q, p-values all <0.05). OAB subjects with anxiety also have more psychosocial difficulties (e.g., more depression, higher stress levels). Among OAB subjects, there were positive correlations between the severity of anxiety symptoms and the severity of $\mathrm{OAB} /$ incontinence symptoms (Spearman's correlation coefficients 0.29 to 0.47 , $\mathrm{p}<0.05$ ). OAB subjects with both anxiety and depression reported higher ICIQ-UI and IIQ-7 scores than those who had anxiety but no depression ( $\mathrm{p}=0.014,0.025$ respectively).

Conclusions-OAB patients reported higher anxiety symptoms compared to controls. OAB patients with anxiety reported more severe $\mathrm{OAB} /$ incontinence symptoms, worse quality of life, and more psychosocial difficulties compared to $\mathrm{OAB}$ patients without anxiety. There are positive correlations between the severity of anxiety symptoms and OAB/incontinence symptoms.

Corresponding author: H. Henry Lai, MD, Division of Urologic Surgery, Department of Surgery, Washington University School of Medicine, 4960 Children's Place, Campus Box 8242, St Louis, MO 63110 USA, laih@wudosis.wustl.edu.

Publisher's Disclaimer: This is a PDF file of an unedited manuscript that has been accepted for publication. As a service to our customers we are providing this early version of the manuscript. The manuscript will undergo copyediting, typesetting, and review of the resulting proof before it is published in its final citable form. Please note that during the production process errors may be discovered which could affect the content, and all legal disclaimers that apply to the journal pertain. 


\section{Keywords}

overactive bladder; urinary incontinence; urinary urgency; anxiety; psychosocial

\section{Introduction}

Overactive bladder (OAB) represents a syndrome characterized by a myriad of lower urinary tract symptoms (LUTS) including urinary urgency, with or without urgency incontinence, usually with frequency and nocturia, in the absence of infection or other identifiable causes. ${ }^{1}$ The true nature of $\mathrm{OAB}$ remains elusive - myogenic changes, neurologic changes, urothelial changes and afferent sensitization have been hypothesized to contribute to the symptomatology of OAB.

Contemporary studies suggested that affective factors might also be associated with OAB (reviewed in ${ }^{2}$ ). Bradley et al (2014) surveyed female veterans who recently returned from deployment to Iraq or Afghanistan and separated from the military. The authors showed that female veterans with anxiety symptoms are more likely to have bothersome urgency incontinence and/or frequency symptoms (odds ratio 2.7). ${ }^{3}$ It was unclear whether this relationship is generalizable to the clinical OAB population since the veteran cohort was young (mean age of 31), and there were high rates of other mental health issues (19\% had post-traumatic stress disorder, $27 \%$ had prior sexual assault). In the EpiLUTS study, which was an internet-based cross-sectional population survey, men and women who reported bothersome urgency and/or urgency incontinence symptoms were more likely to have anxiety than those with minimal symptoms or bother. ${ }^{4-7}$ The limitation of the published literature is that most were population-based symptom surveys. It is unclear if the results from population-based studies are generalizable to the clinical OAB population since a clinical evaluation was not performed, and the clinical diagnosis of OAB could not be ascertained based on self-reported symptoms on surveys (e.g., bladder infection and early interstitial cystitis might mimic OAB symptoms). One study did examine clinic patients and showed higher anxiety scores among "OAB dry" patients, but unfortunately none of the patients in that study had urgency incontinence (there were no "OAB wet" patients). ${ }^{8}$ To our knowledge, no studies have compared $\mathrm{OAB}$ patients with versus without anxiety, or have correlated the severity of their anxiety and $\mathrm{OAB} /$ incontinence symptoms.

Here we address the gap in the literature by specifically investigating the relationship between anxiety and $\mathrm{OAB}$ in the clinical population. We studied OAB patients who presented with bothersome symptoms and sought treatments in clinic, and phenotyped their psychosocial presentation. We also specifically compared OAB patients with versus without anxiety, and studied the correlation between the severity of their anxiety and $\mathrm{OAB} /$ incontinence symptoms. 


\section{Materials and Methods}

\section{Subjects}

Between October 2012 and July 2014, adult patients, aged 18 or above, diagnosed with OAB and age-matched controls without $\mathrm{OAB}$ were recruited into this study that inquired their anxiety and urinary symptoms. For $\mathrm{OAB}$, patients must complain of urinary urgency, with or without urgency incontinence, usually with frequency and nocturia, in the absence of infection or other identifiable causes, in accordance with the 2002 ICS definition of OAB. ${ }^{1}$ The clinical evaluation was performed by one clinician (HL) and followed the published AUA guidelines. ${ }^{9}$ Subjects with a history of urinary incontinence surgery, prostate surgery, urethral stricture disease, neurogenic bladder, urinary retention, pelvic radiation, tuberculosis cystitis, cyclophosphamide cystitis, genitourinary cancer, urinary stones, a documented positive urine culture in the past 6 weeks, or a post-void residual volume $\geq 150$ $\mathrm{mL}$ were not eligible. Controls were recruited by local advertisement and research database. Controls must have no prior diagnosis of $\mathrm{OAB}$ or interstitial cystitis/bladder pain syndrome, no significant lower urinary tract symptoms (AUA symptom index $<7$ ), no bladder or pelvic pain, and no evidence of urinary infection. Controls were age-matched to the OAB cohort. Age matching was operationalized by recruiting similar percentages of patients and controls in the following age bins: $<35,35-49$, and $\geq 50$ years old. All subjects signed an informed consent. The Washington University School of Medicine Institutional Review Board approved this study.

\section{Assessment}

Anxiety symptoms were assessed using the Hospital Anxiety and Depression Scale (HADS). ${ }^{10}$ The questionnaire contains 7 items to assess anxiety symptoms (HADS-A) and 7 items to assess depressive symptoms (HADS-D). A score of $\geq 8$ on the HADS-A was used to operationalize the presence of anxiety. ${ }^{11}$ We have also used a cut-offs of HADS-A 8-10 to indicate mild anxiety and $\geq 11$ for moderate/severe anxiety. The developers of the HADS have recommended these cut-off points for mild (8-10), moderate (11-14), and severe (1521) anxiety, ${ }^{10,11}$ and recent studies have adopted these cut-offs. ${ }^{12}$ To quantify the severity of anxiety symptoms, we have also analyzed the HADS-A data as a continuous variable (HADS-A range 0 to 21).

$\mathrm{OAB} /$ incontinence symptoms were assessed using the following validated questionnaires: 1) International Consultation on Incontinence-Urinary Incontinence Short Form (ICIQ-UI), ${ }^{13}$ 2) International Consultation on Incontinence Overactive Bladder (ICIQ-OAB), ${ }^{14} 3$ ) OAB-q Short Form, ${ }^{15}$ 4) Urogenital Distress Inventory Short Form (UDI-6) ${ }^{16}$, and 5) Incontinence Impact Questionnaire Short Form (IIQ-7). ${ }^{16}$ Briefly, ICIQ-UI is a 4-item questionnaire that assesses the frequency, amount and interference of urinary incontinence. ICIQ-OAB is a 4item questionnaire that inquires about daytime frequency, nighttime frequency, urgency, and urgency incontinence. OAB-q contains two sub-scales that assess symptom bother and condition-specific quality of life. UDI-6 and IIQ-7 measure urinary distress and incontinence impact. 
In addition, the following questionnaires were used to assess other psychosocial factors: 1) depressive symptoms (HADS-D); ${ }^{10}$ 2) Perceived Stress Scale (PSS) to assess the degree to which situations in one's life are perceived as being stressful; 3) Childhood Traumatic Events Scale (CTES) and Recent Traumatic Events Scale (RTES) to inquire about exposure and impact of traumatic life events (e.g., childhood sexual abuse); 4) Poly-Symptomatic, Poly-Syndromic Questionnaire (PSPS-Q) to identify subjects with high somatic symptom burden; 5) PROMIS-Sleep-8B to assess sleep quality; and 6) PROMIS-Fatigue-7A to assess the impact of fatigue on daily life. Details of the questionnaires were described in our previous publication. ${ }^{17}$

\section{Statistical Analysis}

Linear regression models (continuous variables) were used for multivariate comparisons between $\mathrm{OAB}$ and controls, and between the $\mathrm{OAB}$ subgroups (with versus without anxiety, with versus without depression), adjusting for age (continuous variable) and sex. Other potential covariates were not included in the models due to the given sample size.

Spearman's correlation was used for correlation analyses. $\mathrm{P}<0.05$ was considered significant difference. All statistical analysis was completed using the open source statistical package $R$ v3.2.0.

\section{Results \\ Demographics}

Fifty-one adult $\mathrm{OAB}$ patients and 30 age-matched controls participated in this study. Appendix 1 describes the study population (demographics, OAB/incontinence symptoms, quality of life measures, and medical comorbidities). The mean age ( \pm SD) of the OAB and the control groups was $53.8 \pm 11.9$ and $54.2 \pm 12.3$, respectively. There was no significant age or sex difference between OAB subjects and controls ( $\mathrm{p}=0.984$ and 0.14$)$. As expected, $\mathrm{OAB}$ subjects had worse urinary symptoms and quality of life compared to controls.

\section{Comparison of anxiety symptoms between $\mathrm{OAB}$ and controls}

Table 1 compares the anxiety and other psychosocial measures between OAB patients and controls. About half of the OAB subjects (48\%) had anxiety symptoms, and one quarter of OAB subjects (24\%) had moderate to severe anxiety. OAB subjects reported significantly higher anxiety symptoms compared to age-matched controls (HADS-A: $7.5 \pm 4.5$ versus 3.3 \pm 3.6 , $\mathrm{p}<0.001$, mean $\pm \mathrm{SD}$, multivariate linear regression after adjusting for age and sex). A significantly higher percentage of OAB subjects had anxiety (HADS-A $>8$ ) compared to controls ( $48.0 \%$ versus $13.3 \%$, odds ratio $=6.0, \mathrm{p}=0.003$ ). A higher percentage OAB subjects also reported moderate to severe anxiety symptoms (HADS-A $\geq 11$ ) compared to controls (24.0\% versus $3.3 \%$, odds ratio $=9.2, \mathrm{p}=0.025)$.

\section{Comparison of $\mathrm{OAB} / \mathrm{incontinence} \mathrm{symptoms,} \mathrm{quality} \mathrm{of} \mathrm{life,} \mathrm{and} \mathrm{other} \mathrm{psychosocial}$ measures between $O A B$ subjects with and without anxiety}

OAB subjects with anxiety (HADS-A 28 ) reported more severe OAB/incontinence symptoms, greater bother and impact on quality of life compared to OAB subjects without anxiety (HADS-A <8), see Table 2 (ICIQ-UI, ICIQ-OAB, UDI-6, IIQ-7, OAB-q, p-values 
all $<0.05$, multivariate linear regression after adjusting for age and sex). OAB subjects with anxiety also have more psychosocial difficulties-they had more depressive symptoms (HADS-D), higher psychological stress levels (PSS), higher somatic symptom burden (PSPS-Q), and greater impact on sleep quality and fatigue (PROMIS-sleep, PROMISfatigue) compared to OAB subjects without anxiety (p-values all $<0.05$ ).

Since most of the validated urologic questionnaires assess multiple urinary symptoms and presented the results as composite scores, we performed an exploratory analysis to compare the difference in individual symptoms between $\mathrm{OAB}$ subjects with and without anxiety (see Table 3). The results suggested that that anxiety was correlated with urinary incontinence symptoms. Patients with anxiety also reported higher numeric rating of their urgency symptoms $(\mathrm{p}=0.049)$. There was a trend towards higher urinary frequency in patients with anxiety ( $\mathrm{p}=0.061$ for the ICIQ frequency question, $\mathrm{p}=0.084$ for the numeric rating scale of frequency), even though they did not meet criteria for significance, possibly due to small sample size.

\section{Correlation between the severity of anxiety symptoms and $\mathrm{OAB} /$ incontinence symptoms}

To quantify the severity of anxiety symptoms, we have also analyzed the HADS-A data as a continuous variable (HADS-A range 0 to 21). We then performed Spearman's correlation analyses between HADS-A and the various urinary, quality of life, and psychosocial measures (see Table 4). Among OAB subjects, there were positive correlations between the severity of anxiety symptoms (HADS-A) and the severity of OAB/incontinence symptoms, greater bother and impact on quality of life (ICIQ-UI, ICIQ-OAB, UDI-6, IIQ-7, OAB-q, Spearman's correlation coefficients 0.29 to 0.47 , p-values all $<0.05$ ). There were also positive correlations between the severity of anxiety and depressive symptoms, psychological stress levels, somatic symptom burden, sleep quality and fatigue (HADS-D, PSS, PSPS-Q, PROMIS, p all <0.05).

\section{$\mathrm{OAB} /$ incontinence symptoms in $\mathrm{OAB}$ patients with both anxiety and depression}

Since there was a strong correlation between anxiety and depressive symptoms (Spearman's correlation $=0.77, \mathrm{p}<0.001$, see Table 4), we studied the influence of depression on the results. We compared the $\mathrm{OAB} /$ incontinence symptoms and quality of life measures among OAB subjects who had both anxiety and depression (HADS-A $\geq 8$ and HADS-D $\geq 8$ ) versus those who had anxiety but no depression (HADS-A $\geq 8$ and HADS-D <8). OAB subjects with both anxiety and depression reported higher ICIQ-UI and IIQ-7 scores than those who had anxiety but no depression ( $\mathrm{p}=0.014,0.025$ respectively, see Appendix 2). However no difference was noted in ICIQ-OAB, UDI-6 or OAB-q.

\section{Comment}

The main findings of this study are: 1) anxiety is prevalent among the clinical population half of the OAB subjects had anxiety symptoms, and one quarter of OAB subjects had moderate to severe anxiety symptoms; 2) OAB subjects reported higher anxiety symptoms compared to controls; 3 ) OAB patients with anxiety reported more severe OAB/incontinence symptoms, worse quality of life, and more psychosocial difficulties compared to OAB 
patients without anxiety; and 4) there is a strong dose-response relationship between the severity of anxiety and $\mathrm{OAB} /$ incontinence symptoms.

Anxiety and $\mathrm{OAB}$ are both prevalent in the population. The prevalence of anxiety disorders in is estimated to be around $11-18 \%,{ }^{18}$ while OAB affects $12-16 \%$ of adults in the population. One important research question is whether anxiety is causally related to $\mathrm{OAB}$, or whether it is mere association or co-incidence. It is also not clear if anxiety is a causal factor for $\mathrm{OAB}$ symptoms or results from having these bladder symptoms (e.g.. the fear about finding a bathroom in time may cause anxiety). We suspect the link between anxiety and $\mathrm{OAB}$ is complex and multifactorial. To try to understand this relationship, we have applied the criteria outlined by Hill (1965) to examine for evidence of causality. ${ }^{19}$ Data from this and other studies suggest that anxiety and $\mathrm{OAB} /$ incontinence might be casually related. First, the strength of association is significant - the odds ratios of having anxiety and moderate/severe anxiety in $\mathrm{OAB}$ versus healthy controls were 6.0 and 9.2 respectively in our study. In the veteran study by Bradley et al, the odd ratios were $2.7-3.5 .{ }^{3}$ Second, the association between anxiety and $\mathrm{OAB}$ has been consistently demonstrated in this and other studies, across different study population (clinical population in this study, female veterans in Bradley et al, ${ }^{3}$ internet surveys in the EpiLUTS study ${ }^{4-7}$ ) and in different countries (US, UK, Sweden, and others ${ }^{20,21}$ ). Third, we have demonstrated a strong dose-response or gradient relationship between anxiety and $\mathrm{OAB} /$ incontinence symptoms. Fourth, temporal relationships have been demonstrated in two longitudinal studies. The presence of urgency incontinence at baseline increased the odds of developing anxiety at 10 years, and conversely the presence of anxiety at baseline increased the odds of developing urgency incontinence at 10 years in a Norwegian study. ${ }^{12}$ Bidirectional temporal relationship was also observed in a one-year longitudinal study from the UK. ${ }^{22}$ Fifth, successful management of OAB symptoms with medications reduced the anxiety symptoms. ${ }^{23}$ Finally, the association between $\mathrm{OAB}$ and anxiety appears to be biologically plausible (see below).

There is evidence in the basic science literature that anxiety and $\mathrm{OAB} /$ incontinence might have shared biological pathways. The serotonergic pathway appears to play various roles in anxiety. ${ }^{24}$ Reduction of serotonin levels in the central nervous system is associated with urinary frequency and bladder contractions, while activation of the central serotonergic system with a 5-HT uptake inhibitor depresses reflex bladder contractions and increases the micturition threshold volume in animal studies. ${ }^{25}$ Anxiety may thus be linked to OAB/ incontinence via the serotonergic pathway. In fact, the serotonin-noradrenaline reuptake inhibitor (SNRI) duloxetine has been shown to improve the "wet" and "dry" symptoms of $\mathrm{OAB}$ in patients. ${ }^{26}$ Another potential shared mechanism might be dysregulation of the hypothalamic-pituitary-adrenal (HPA) axis, resulting in increased corticotropin-releasing factor (CRF) release. CRF may play a role in anxiety disorders. ${ }^{27}$ Administration of CRF stimulates bladder function (lowers the micturition threshold, intercontraction interval and micturition volume) whereas treatment with a CRF antagonist reduces detrusor overactivity in rat models of detrusor overactivity and anxiety. ${ }^{28}$

Although the mechanisms are biologically plausible, the evidence is based primarily on animal studies, and the potential shared mechanisms need to be formally studied in the clinical population. Overall, the mechanistic link between anxiety and OAB remains 
suboptimally explained. This gap of knowledge may pave way for an improved understanding of the mechanisms governing $\mathrm{OAB}$, with a potential for more targeted pharmacotherapy.

In this study we have focused primarily on anxiety. However in previous studies we have also examined other psychosocial issues such as stress levels and exposure to childhood sexual trauma in the OAB population. ${ }^{17,29}$ Collectively our studies demonstrated the significant psychosocial morbidities experienced by $\mathrm{OAB}$ patients. It is possible that psychosocial factors may cause, maintain, and modulate $\mathrm{OAB} /$ incontinence and other lower urinary tract symptoms (LUTS) through these shared biological pathways. And if that is true, this may have therapeutic implications since adjuvant psychological intervention may have the potential to improve clinical outcome in urologic conditions. There was evidence that psychological therapy (defined as anxiety reduction, counseling and support in the study) improved urinary urgency and incontinence but not urinary frequency (which responded better to bladder training alone) ${ }^{30}$ In light of these data, it may be worthwhile to study adjuvant psychological interventional trials for selected OAB patients in the future. It may also be important to study how anxiety modulates the clinical response to traditional $\mathrm{OAB}$ treatments. We recommend that psychosocial factors such as anxiety be assessed in patients with $\mathrm{OAB}$, in addition to the traditional urologic factors.

The current study has limitations: 1) It was a single-institution study with small sample size, thus it may not have sufficient power for more detailed analyses (for example, comparison of anxiety and psychosocial factors between OAB patients with versus without incontinence, or adjusting for additional potential covariates such as medical comorbidities in the multivariate analysis); 2) findings from patients seeking care at a tertiary center because of the severity of their symptoms may not be generalizable to the general OAB population; and 3 ) assessment of anxiety was based on self-reported symptoms. Although the HADS-A is commonly used to assess for anxiety in the outpatient setting, it is not a diagnostic tool for anxiety disorder, and cannot be ascertained without psychiatric evaluation which were not performed here. Despite these limitations, many of the comparisons clearly demonstrated differences. Large multi-institutional studies of the clinical OAB population are needed to further examine these relationships.

\section{Conclusions}

$\mathrm{OAB}$ patients reported higher anxiety symptoms compared to controls. OAB patients with anxiety reported more severe $\mathrm{OAB} /$ incontinence symptoms, worse quality of life, and more psychosocial difficulties compared to OAB patients without anxiety. There are positive correlations between the severity of anxiety symptoms and $\mathrm{OAB} /$ incontinence symptoms.

\section{Acknowledgments}

The study was partly supported by the National Institutes of Health grants P20-DK-097798 and K08-DK-094964 We would like to thank all the subjects who participated in the study, Vivien Gardner for recruiting the subjects, Alexandra Kim for protocol development, and Alethea Paradis for data management (Division of Urologic Surgery). Research reported in this publication was supported by the Washington University Institute of Clinical and Translational Sciences grant UL1TR000448 from the National Center for Advancing Translational Sciences 
(NCATS) of the National Institutes of Health (NIH). The content is solely the responsibility of the authors and does not necessarily represent the official view of the NIH.

\section{Abbreviations}

HADS-A hospital anxiety and depression scale-anxiety subscale

ICIQ international consultation on incontinence

IIQ-7 incontinence impact questionnaire short form

OAB overactive bladder

UDI-6 urogenital distress inventory short form

UI urinary incontinence

\section{References}

1. Abrams P, Cardozo L, Fall M, Griffiths D, Rosier P, Ulmsten U, van Kerrebroeck P, Victor A, Wein A. The standardisation of terminology of lower urinary tract function: report from the Standardisation Sub-committee of the International Continence Society. Neurourol Urodyn. 2002; 21:167-78. [PubMed: 11857671]

2. Vrijens D, Drossaerts J, van Koeveringe G, Van Kerrebroeck P, van Os J, Leue C. Affective symptoms and the overactive bladder - a systematic review. J Psychosom Res. 2015; 78:95-108. [PubMed: 25499886]

3. Bradley CS, Nygaard IE, Torner JC, Hillis SL, Johnson S, Sadler AG. Overactive bladder and mental health symptoms in recently deployed female veterans. J Urol. 2014; 191:1327-32. [PubMed: 24316095]

4. Coyne KS, Kvasz M, Ireland AM, Milsom I, Kopp ZS, Chapple CR. Urinary incontinence and its relationship to mental health and health-related quality of life in men and women in Sweden, the United Kingdom, and the United States. Eur Urol. 2012; 61:88-95. [PubMed: 21831517]

5. Coyne KS, Sexton CC, Kopp ZS, Ebel-Bitoun C, Milsom I, Chapple C. The impact of overactive bladder on mental health, work productivity and health-related quality of life in the UK and Sweden: results from EpiLUTS. BJU Int. 2011; 108:1459-71. [PubMed: 21371240]

6. Milsom I, Kaplan SA, Coyne KS, Sexton CC, Kopp ZS. Effect of bothersome overactive bladder symptoms on health-related quality of life, anxiety, depression, and treatment seeking in the United States: results from EpiLUTS. Urology. 2012; 80:90-6. [PubMed: 22748867]

7. Sexton CC, Coyne KS, Thompson C, Bavendam T, Chen CI, Markland A. Prevalence and effect on health-related quality of life of overactive bladder in older americans: results from the epidemiology of lower urinary tract symptoms study. J Am Geriatr Soc. 2011; 59:1465-70. [PubMed: 21718275]

8. Knight S, Luft J, Nakagawa S, Katzman WB. Comparisons of pelvic floor muscle performance, anxiety, quality of life and life stress in women with dry overactive bladder compared with asymptomatic women. BJU Int. 2012; 109:1685-9. [PubMed: 21995304]

9. Gormley EA, Lightner DJ, Burgio KL, Chai TC, Clemens JQ, Culkin DJ, Das AK, Foster HE Jr, Scarpero HM, Tessier CD, et al. Diagnosis and treatment of overactive bladder (non-neurogenic) in adults: AUA/SUFU guideline. J Urol. 2012; 188:2455-63. [PubMed: 23098785]

10. Zigmond AS, Snaith RP. The hospital anxiety and depression scale. Acta Psychiatr Scand. 1983; 67:361-70. [PubMed: 6880820]

11. Herrmann C. International experiences with the Hospital Anxiety and Depression Scale--a review of validation data and clinical results. J Psychosom Res. 1997; 42:17-41. [PubMed: 9055211]

12. Felde G, Ebbesen MH, Hunskaar S. Anxiety and depression associated with urinary incontinence. A 10-year follow-up study from the Norwegian HUNT study (EPINCONT). Neurourol Urodyn. 2015 
13. Avery K, Donovan J, Peters TJ, Shaw C, Gotoh M, Abrams P. ICIQ: a brief and robust measure for evaluating the symptoms and impact of urinary incontinence. Neurourol Urodyn. 2004; 23:32230. [PubMed: 15227649]

14. Jackson S, Donovan J, Brookes S, Eckford S, Swithinbank L, Abrams P. The Bristol Female Lower Urinary Tract Symptoms questionnaire: development and psychometric testing. Br J Urol. 1996; 77:805-12. [PubMed: 8705212]

15. Coyne K, Revicki D, Hunt T, Corey R, Stewart W, Bentkover J, Kurth H, Abrams P. Psychometric validation of an overactive bladder symptom and health-related quality of life questionnaire: the OAB-q. Qual Life Res. 2002; 11:563-74. [PubMed: 12206577]

16. Uebersax JS, Wyman JF, Shumaker SA, McClish DK, Fantl JA. Short forms to assess life quality and symptom distress for urinary incontinence in women: the Incontinence Impact Questionnaire and the Urogenital Distress Inventory. Continence Program for Women Research Group. Neurourol Urodyn. 1995; 14:131-9. [PubMed: 7780440]

17. Lai HH, Morgan CD, Vetter J, Andriole GL. Impact of childhood and recent traumatic events on the clinical presentation of overactive bladder. Neurourol Urodyn. 2015

18. Kessler RC, Chiu WT, Demler O, Merikangas KR, Walters EE. Prevalence, severity, and comorbidity of 12-month DSM-IV disorders in the National Comorbidity Survey Replication. Arch Gen Psychiatry. 2005; 62:617-27. [PubMed: 15939839]

19. Hill AB. The Environment and Disease. Association or Causation? Proc R Soc Med. 1965; 58:295-300. [PubMed: 14283879]

20. Yoo ES, Kim BS, Kim DY, Oh SJ, Kim JC. The impact of overactive bladder on health-related quality of life, sexual life and psychological health in Korea. Int Neurourol J. 2011; 15:143-51. [PubMed: 22087423]

21. Felde G, Bjelland I, Hunskaar S. Anxiety and depression associated with incontinence in middleaged women: a large Norwegian cross-sectional study. Int Urogynecol J. 2012; 23:299-306. [PubMed: 22068320]

22. Perry S, McGrother CW, Turner K. Leicestershire MRCISG. An investigation of the relationship between anxiety and depression and urge incontinence in women: development of a psychological model. Br J Health Psychol. 2006; 11:463-82. [PubMed: 16870056]

23. Rogers R, Bachmann G, Jumadilova Z, Sun F, Morrow JD, Guan Z, Bavendam T. Efficacy of tolterodine on overactive bladder symptoms and sexual and emotional quality of life in sexually active women. Int Urogynecol J Pelvic Floor Dysfunct. 2008; 19:1551-7. [PubMed: 18685795]

24. Gordon JA, Hen R. The serotonergic system and anxiety. Neuromolecular Med. 2004; 5:27-40. [PubMed: 15001810]

25. de Groat WC. Influence of central serotonergic mechanisms on lower urinary tract function. Urology. 2002; 59:30-6. [PubMed: 12007520]

26. Steers WD, Herschorn S, Kreder KJ, Moore K, Strohbehn K, Yalcin I, Bump RC. Duloxetine compared with placebo for treating women with symptoms of overactive bladder. BJU Int. 2007; 100:337-45. [PubMed: 17511767]

27. Arborelius L, Owens MJ, Plotsky PM, Nemeroff CB. The role of corticotropin-releasing factor in depression and anxiety disorders. J Endocrinol. 1999; 160:1-12. [PubMed: 9854171]

28. Klausner AP, Streng T, Na YG, Raju J, Batts TW, Tuttle JB, Andersson KE, Steers WD. The role of corticotropin releasing factor and its antagonist, astressin, on micturition in the rat. Auton Neurosci. 2005; 123:26-35. [PubMed: 16256445]

29. Lai H, Gardner V, Vetter J, Andriole GL. Correlation between psychological stress levels and the severity of overactive bladder symptoms. BMC Urol. 2015; 15:14. [PubMed: 25887525]

30. Macaulay AJ, Stern RS, Holmes DM, Stanton SL. Micturition and the mind: psychological factors in the aetiology and treatment of urinary symptoms in women. Br Med J (Clin Res Ed). 1987; 294:540-3. 


\section{Appendix 1}

Description of the study population

\begin{tabular}{|c|c|c|c|}
\hline & OAB & Controls & $\begin{array}{l}\text { p-value (adjusted for } \\
\text { age and sex) }\end{array}$ \\
\hline \multicolumn{4}{|l|}{ Demographics: } \\
\hline No. of subjects & 51 & 30 & \\
\hline Age (mean \pm SD) & $53.8 \pm 11.9$ & $54.2 \pm 12.3$ & 0.98 \\
\hline Sex (\% females) & $73 \%$ & $57 \%$ & 0.14 \\
\hline Race (\% white) & $43.1 \%$ & $63.3 \%$ & 0.08 \\
\hline Age of diagnosis of $\mathrm{OAB}($ mean $\pm \mathrm{SD})$ & $47.5 \pm 15.2$ & Not applicable & \\
\hline$\%$ with OAB symptoms less than one year? & $24 \%$ & Not applicable & \\
\hline \multicolumn{4}{|l|}{ Urinary symptoms: $($ mean \pm SD) } \\
\hline No. of daytime void ${ }^{a}$ & $1.8 \pm 1.3$ & $0.2 \pm 0.6$ & $<0.001$ \\
\hline No of nighttime void $b$ & $2.6 \pm 1.1$ & $0.9 \pm 0.7$ & $<0.001$ \\
\hline How often rush to bathroom to void ${ }^{c}$ & $2.7 \pm 0.9$ & $0.6 \pm 0.7$ & $<0.001$ \\
\hline How often does urine leak before getting to the bathroom? ${ }^{d}$ & $2.2 \pm 0.9$ & $0.3 \pm 0.5$ & $<0.001$ \\
\hline \multicolumn{4}{|l|}{ Urinary questionnaires: $($ mean $\pm \mathrm{SD}$ ) } \\
\hline ICIQ-UI (urinary incontinence, 0-21) & $12.0 \pm 4.9$ & $1.4 \pm 2.0$ & $<0.001$ \\
\hline ICIQ-OAB (overactive bladder, 0-16) & $9.3 \pm 2.6$ & $2.0 \pm 1.5$ & $<0.001$ \\
\hline OAB-q symptom bother subscale (6-36) & $19.1 \pm 6.6$ & $2.2 \pm 2.8$ & $<0.001$ \\
\hline OAB-q quality of life subscale (13-78) & $29.7 \pm 16.9$ & $2.0 \pm 3.0$ & $<0.001$ \\
\hline UDI-6 (urogenital distress inventory, 0-24) & $12.6 \pm 5.6$ & $0.9 \pm 1.4$ & $<0.001$ \\
\hline IIQ-7 (incontinence impact questionnaire, 0-28) & $8.8 \pm 8.2$ & $0.1 \pm 0.4$ & $<0.001$ \\
\hline \multicolumn{4}{|l|}{ Medical comorbidities: } \\
\hline Hypertension & $37 \%$ & $33 \%$ & 0.72 \\
\hline Diabetes & $8 \%$ & $3 \%$ & 0.31 \\
\hline Stroke, transient ischemic attack & $8 \%$ & $7 \%$ & 0.15 \\
\hline MI, angina & $0 \%$ & $0 \%$ & 1.00 \\
\hline
\end{tabular}

Based on the categories of response on the ICIQ-OAB questionnaire:

${ }^{a}$ How many times do you urinate during the day? $0=1$ to 6 times, $1=7$ to 8 times $2=9$ to 10 times, $3=11$ to 12 times, $4=13$ or more times.

$b$ During the night, how many times do you have to get up to urinate, on average? $0=$ none, $1=$ one time, $2=$ two times, $3=$ three times, $4=$ four or more times

$c$ Do you have to rush to the toilet to urinate? $0=$ never, $1=$ occasionally, $2=$ sometimes, $3=$ most of the time, $4=$ all of the time $d$ Does urine leak before you can get to the toilet? $0=$ never, $1=$ occasionally, $2=$ sometimes, $3=$ most of the time, $4=$ all of the time 


\section{Appendix 2}

$\mathrm{OAB}$ with both anxiety and depression versus $\mathrm{OAB}$ with anxiety but no depression (adjusted for age and sex)

\begin{tabular}{|l|l|l|l|}
\hline & $\begin{array}{l}\text { OAB with both } \\
\text { anxiety and } \\
\text { depression (HADS-A } \\
\geq 8 \text { and HADS-D } \geq 8)\end{array}$ & $\begin{array}{l}\text { OAB with anxiety } \\
\text { but no depression } \\
\text { HADS-A } \geq 8 \text { and } \\
\text { HADS-D <8) }\end{array}$ & $\begin{array}{l}\text { p-value } \\
\text { adjusted for } \\
\text { age and sex) }\end{array}$ \\
\hline Demographics: & & & \\
\hline No. of subjects & 13 & 11 & \\
\hline Age (mean \pm SD) & $56.5 \pm 10.3$ & $52.2 \pm 12.0$ & 0.384 \\
\hline Sex (\% females) & $61.5 \%$ & $81.8 \%$ & 0.386 \\
\hline HADS-A scores & $12.0 \pm 2.7$ & $10.5 \pm 3$ & 0.161 \\
\hline HADS-D scores & $10.4 \pm 2.5$ & $5.2 \pm 2$ & $<0.001$ \\
\hline Urinary questionnaires: (mean \pm SD) & & & 0.014 \\
\hline ICIQ-UI (urinary incontinence, 0-21) & $16.2 \pm 3.6$ & $12 \pm 4.7$ & 0.891 \\
\hline ICIQ-OAB (overactive bladder, 0-16) & $10.2 \pm 3.2$ & $10.3 \pm 2.1$ & 0.611 \\
\hline OAB-q symptom bother subscale (6-36) & $20.8 \pm 6.9$ & $22.5 \pm 5.2$ & 0.607 \\
\hline OAB-q quality of life subscale (13-78) & $38.8 \pm 17.8$ & $34.5 \pm 18.1$ & 0.639 \\
\hline UDI-6 (urogenital distress inventory, 0-24) & $15.8 \pm 6.3$ & $14.6 \pm 5.6$ & 0.025 \\
\hline $\begin{array}{l}\text { IIQ-7 (incontinence impact questionnaire, } \\
\text { 0-28) }\end{array}$ & $16.6 \pm 8.5$ & $8.0 \pm 7.3$ & \\
\hline
\end{tabular}




\section{Table 1}

Comparison of anxiety and other psychosocial measures between $\mathrm{OAB}$ and controls (adjusted for age and sex)

\begin{tabular}{|l|l|l|l|}
\hline & OAB (n=50) & Controls (n=30) & $\begin{array}{l}\text { p-value (adjusted } \\
\text { for age and sex) }\end{array}$ \\
\hline Anxiety measures: & & & \\
\hline HADS-A (mean \pm SD) & $7.5 \pm 4.5$ & $3.3 \pm 3.6$ & $<0.001$ \\
\hline \% with HADS-A 28 (presence of anxiety) & $48.0 \%$ & $13.3 \%$ & 0.003 \\
\hline $\begin{array}{l}\text { Odds ratio of having anxiety (HADS-A } \$ \text { ) in OAB compared to } \\
\text { controls (95\% CI) }\end{array}$ & OR=6.0 (CI: 1.8 to 19.7) & & \\
\hline \% with HADS-A $\geq 11$ (moderate to severe anxiety) & $24.0 \%$ & $3.3 \%$ & 0.025 \\
\hline $\begin{array}{l}\text { Odds ratio of having moderate/severe anxiety (HADS-A } \geq 11) \text { in OAB } \\
\text { compared to controls (95\% CI) }\end{array}$ & OR=9.2 (CI: 1.1 to 74.6) & & \\
\hline Other psychosocial measures: (mean \pm SD) & & & \\
\hline Depression (HADS- D) & $5.3 \pm 3.9$ & $2.8 \pm 3.9$ & 0.004 \\
\hline Psychological stress level (PSS) & $17.3 \pm 8.1$ & $10.7 \pm 8.5$ & 0.001 \\
\hline Somatic symptom burden (PSPS-Q) & $17.5 \pm 12.3$ & $6.4 \pm 7.9$ & $<0.001$ \\
\hline Exposure to childhood sexual & $29.4 \%$ & $6.7 \%$ & 0.040 \\
\hline trauma (CTES) & & & \\
\hline Sleep (PROMIS- 8b) & $54.3 \pm 10.3$ & $43.8 \pm 9.2$ & $<0.001$ \\
\hline Fatigue (PROMIS- 7a) & $54.7 \pm 9.6$ & $46.0 \pm 6.4$ & $<0.001$ \\
\hline
\end{tabular}

* One OAB patient did not provide complete HADS-A data and was thus excluded from comparisons. 


\section{Table 2}

Comparison of $\mathrm{OAB} /$ incontinence, anxiety and other psychosocial measures between $\mathrm{OAB}$ with anxiety versus $\mathrm{OAB}$ without anxiety (adjusted for age and sex)

\begin{tabular}{|l|l|l|l|}
\hline & $\begin{array}{l}\text { OAB with anxiety (HADS- } \\
\mathbf{A ~} \mathbf{8} \text { ) }\end{array}$ & $\begin{array}{l}\text { OAB without anxiety } \\
\text { (HADS-A <8) }\end{array}$ & $\begin{array}{l}\text { p-value (adjusted for age } \\
\text { and sex) }\end{array}$ \\
\hline Demographics: & & & \\
\hline No. of subjects* & 24 & 26 & \\
\hline Age (mean \pm SD) & $54.5 \pm 11.1$ & $53.1 \pm 13.1$ & 0.85 \\
\hline Sex (\% females) & $70.8 \%$ & $73.1 \%$ & 0.86 \\
\hline HADS-A scores & $11.3 \pm 2.9$ & $3.9 \pm 2.3$ & $<0.001$ \\
\hline Urinary questionnaires: (mean \pm SD) & & & \\
\hline ICIQ-UI (urinary incontinence, 0-21) & $14.3 \pm 4.6$ & $10.3 \pm 4.2$ & 0.002 \\
\hline ICIQ-OAB (overactive bladder, 0-16) & $10.3 \pm 2.8$ & $8.5 \pm 2.3$ & 0.011 \\
\hline OAB-q symptom bother subscale (6-36) & $21.6 \pm 6.1$ & $17.1 \pm 5.8$ & 0.007 \\
\hline OAB-q quality of life subscale (13-78) & $36.9 \pm 17.7$ & $22.6 \pm 11.9$ & 0.004 \\
\hline UDI-6 (urogenital distress inventory, 0-24) & $15.3 \pm 5.9$ & $10.1 \pm 4.3$ & 0.001 \\
\hline IIQ-7 (incontinence impact questionnaire, 0-28) & $12.7 \pm 9$ & $5.3 \pm 5.6$ & 0.001 \\
\hline Other psychosocial measures: (mean \pm SD) & & & \\
\hline Depression (HADS-D) & $8.0 \pm 3.5$ & $2.5 \pm 3.5$ & $<0.001$ \\
\hline Psychological stress level (PSS) & $23.1 \pm 6.3$ & $11.8 \pm 5.5$ & $<0.001$ \\
\hline Somatic symptom burden (PSPS- Q) & $24.5 \pm 11.3$ & $11.0 \pm 9.6$ & $<0.001$ \\
\hline Exposure to childhood sexual trauma (CTES) & $37.5 \%$ & $23.1 \%$ & 0.162 \\
\hline Sleep (PROMIS-8b) & $58.2 \pm 10.1$ & $50.7 \pm 9.6$ & 0.012 \\
\hline Fatigue (PROMIS-7a) & $59.2 \pm 8.8$ & $50.5 \pm 8.6$ & 0.001 \\
\hline
\end{tabular}


Table 3

Comparison of individual urinary symptoms (adjusted for age and sex)

\begin{tabular}{|c|c|c|c|c|}
\hline & $\begin{array}{l}\text { OAB with } \\
\text { anxiety } \\
\text { (HADS-A } \\
\geq 8 \text { ) }\end{array}$ & $\begin{array}{l}\text { OAB } \\
\text { without } \\
\text { anxiety } \\
\text { (HADS-A } \\
<8 \text { ) }\end{array}$ & $\begin{array}{l}\text { p-value } \\
\text { (adjusted for } \\
\text { age and sex) }\end{array}$ & Source of question \\
\hline \multicolumn{5}{|l|}{ Incontinence symptoms: } \\
\hline How often do you leak urine? ${ }^{a}$ & $3.8 \pm 1.3$ & $2.7 \pm 1.2$ & 0.003 & ICIQ-UI question 3 \\
\hline How much urine do you usually leak? $b$ & $3.4 \pm 1.6$ & $2.2 \pm 1.1$ & 0.002 & ICIQ-UI question 4 \\
\hline Does urine leak before you can get to the toilet? ${ }^{c}$ & $2.5 \pm 0.9$ & $2.0 \pm 0.7$ & 0.022 & ICIQ-OAB question 6a \\
\hline \multicolumn{5}{|l|}{ Frequency symptoms: } \\
\hline How many times do you urinate during the day? $d$ & $2.0 \pm 1.4$ & $1.5 \pm 1.0$ & 0.061 & ICIQ-OAB question 3a \\
\hline $\begin{array}{l}\text { During the night, how many times do you have to get } \\
\text { up to urinate, on average? }\end{array}$ & $2.8 \pm 1$ & $2.5 \pm 1.1$ & 0.366 & ICIQ-OAB question $4 \mathrm{a}$ \\
\hline Numeric rating scale of frequency $(0-10)$ & $7.1 \pm 2.6$ & $5.9 \pm 2.3$ & 0.084 & \\
\hline \multicolumn{5}{|l|}{ Urgency symptoms: } \\
\hline Do you have to rush to the toilet to urinate? $f$ & $2.9 \pm 0.8$ & $2.5 \pm 0.9$ & 0.056 & ICIQ-OAB question $5 \mathrm{a}$ \\
\hline Numeric rating scale of urgency $(0-10)$ & $6.9 \pm 2.8$ & $5.5 \pm 2.1$ & 0.049 & \\
\hline USS (urgency severity scale, $0-3$ ) $g$ & $2.3 \pm 0.7$ & $2 \pm 0.7$ & 0.134 & $\begin{array}{l}\text { USS is a 4- point self- reported } \\
\text { rating scale of the degree of } \\
\text { urgency sensation (none, mild, } \\
\text { moderate, severe). } g\end{array}$ \\
\hline
\end{tabular}

Based on the categories of response on the ICIQ questionnaire:

${ }^{a}$ How often do you leak urine? $0=$ never, $1=$ about once a week or less often, $2=$ two or three times a week, $3=$ about once a day, $4=$ several times a day, $5=$ all the time.

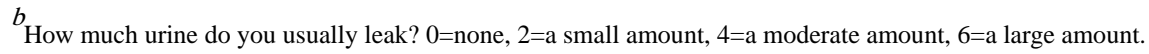

$c$ Does urine leak before you can get to the toilet? $0=$ never, $1=$ occasionally, $2=$ sometimes, $3=$ most of the time, $4=$ all of the time.

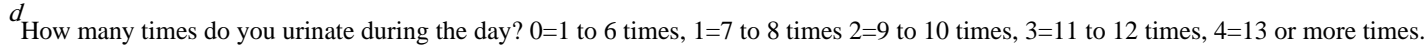

During the night, how many times do you have to get up to urinate, on average? $0=$ none, $1=$ one time, $2=$ two times, $3=$ three times, $4=$ four or more times

$f$ Do you have to rush to the toilet to urinate? $0=$ never, $1=$ occasionally, $2=$ sometimes, $3=$ most of the time, $4=$ all of the time.

${ }^{g}$ Urgency severity scale (USS) reference: Nixon, A., Colman, S., Sabounjian, L. et al.: A validated patient reported measure of urinary urgency severity in overactive bladder for use in clinical trials. J Urol, 174: 604, 2005. 


\section{Table 4}

Spearman's correlation analyses between the severity of anxiety symptoms (HADS-A, range 0-21) and OAB/ incontinence symptoms.

\begin{tabular}{|l|l|l|}
\hline & Spearman's correlation coefficient & $\begin{array}{l}\text { p-value (multivariate linear regression, adjusted } \\
\text { for age and sex) }\end{array}$ \\
\hline Urinary questionnaires: & & \\
\hline ICIQ-UI (urinary incontinence, 0-21) & 0.41 & 0.003 \\
\hline ICIQ-OAB (overactive bladder, 0-16) & 0.34 & 0.009 \\
\hline OAB-q symptom bother subscale (6-36) & 0.29 & 0.021 \\
\hline OAB-q quality of life subscale (13-78) & 0.40 & 0.006 \\
\hline UDI-6 (urogenital distress inventory, 0-24) & 0.37 & $<0.001$ \\
\hline IIQ-7 (incontinence impact questionnaire, 0-28) & 0.47 & $<0.001$ \\
\hline Other psychosocial measures: & & \\
\hline Depression (HADS-D) & 0.77 & $<0.001$ \\
\hline Psychological stress level (PSS) & 0.82 & $<0.001$ \\
\hline Somatic symptom burden (PSPS- Q) & 0.47 & 0.001 \\
\hline Sleep (PROMIS-8b) & 0.38 & 0.003 \\
\hline Fatigue (PROMIS-7a) & 0.50 & $<0.001$ \\
\hline
\end{tabular}

